\title{
Article \\ Modified Hexagonal Split Ring Resonator Based on an Epsilon-Negative Metamaterial for Triple-Band Satellite Communication
}

\author{
Salah Uddin Afsar ${ }^{1}$, Mohammad Rashed Iqbal Faruque 1,*D, Mohammad Jakir Hossain ${ }^{2}$, \\ Mayeen Uddin Khandaker ${ }^{3} \mathbb{D}$, Hamid Osman ${ }^{4}$ and Sultan Alamri ${ }^{4}$ (D)
}

1 Space Science Centre (ANGKASA), Institute of Climate Change (IPI), Universiti Kebangsaan Malaysia, Bangi 43600, Malaysia; P108627@siswa.ukm.edu.my

2 Department of Electrical and Electronic Engineering, Dhaka University of Engineering \& Technology (DUET), Gazipur 1707, Bangladesh; mohd.jakirhossain@gmail.com

3 Centre for Applied Physics and Radiation Technologies, School of Engineering and Technology, Sunway University, Bandar Sunway 47500, Malaysia; mayeenk@sunway.edu.my

4 Department of Radiological Sciences, College of Applied Medical Sciences, Taif University, Taif 21944, Saudi Arabia; ha.osman@tu.edu.sa (H.O.); s.alamri@tu.edu.sa (S.A.)

* Correspondence: rashed@ukm.edu.my

check for updates

Citation: Afsar, S.U.; Faruque, M.R.I.; Hossain, M.J.; Khandaker, M.U.; Osman, H.; Alamri, S. Modified Hexagonal Split Ring Resonator Based on an Epsilon-Negative Metamaterial for Triple-Band Satellite Communication. Micromachines 2021, 12, 878. https://doi.org/10.3390/ mi12080878

Academic Editor: Piotr Kurgan

Received: 29 June 2021

Accepted: 23 July 2021

Published: 26 July 2021

Publisher's Note: MDPI stays neutral with regard to jurisdictional claims in published maps and institutional affiliations.

Copyright: (c) 2021 by the authors. Licensee MDPI, Basel, Switzerland. This article is an open access article distributed under the terms and conditions of the Creative Commons Attribution (CC BY) license (https:/ / creativecommons.org/licenses/by/ $4.0 /)$.

\begin{abstract}
A triple-band epsilon-negative (ENG) metamaterial based on a split ring resonator (SSR) with a modified hexagonal-shaped metal strip proposed in this study is a new combination of a single slit square resonator and a modified hexagonal-shaped metal strip. The desired unit cell FR-4 (lossy) that was selected as the substrate was $1.6 \mathrm{~mm}$ thick. Following the assessment of the unit cell, a high-frequency electromagnetic simulator like the computer simulation technology (CST) microwave studio was applied to assess the S-parameters. The proposed design exhibited resonance at $2.89,9.42$, and $15.16 \mathrm{GHz}$. The unit cell also demonstrated negative permittivity in the frequency ranges $2.912-3.728 \mathrm{GHz}, 9.552-10.144 \mathrm{GHz}$, and $15.216-17.328 \mathrm{GHz}$, along with a negative refractive index. An effective medium ratio (EMR) of 11.53 is an indicator of the goodness of the metamaterial unit cell. It is deliberate at the lowermost resonance frequency of $2.89 \mathrm{GHz}$. Moreover, the simulated results that were validated using HFSS and equivalent circuit model indicated slight variations. The proposed design was finalised based on several parametric studies, including design optimisation, different unit cell sizes, various substrate materials, and different electromagnetic (EM) field propagations. The proposed triple band (, $\mathrm{X}$, and $\mathrm{Ku}$ bands) negative permittivity metamaterial unit cell can be utilised for various wireless applications, such as microwave communication, satellite communication, and long-distance radio communication.
\end{abstract}

Keywords: triple band; SSR; $\varepsilon$-negative material; satellite communication

\section{Introduction}

Materials found in natural surroundings can achieve positive permittivity and permeability. Contrarily, metamaterials yield both negative permittivity and negative permeability or either trait can be negative by itself. An engineered structure indicating both negative permittivity and permeability is called a double negative (DNG) metamaterial, while a structure manifesting either negative value is called a single negative (SNG) metamaterial [1,2]. DNG and SNG metamaterials are extensively used in different technological developments. The use of metamaterials in synthetic dielectrics of microwave application began just after the Second World War. The advancements in material sciences led to the industrialisation of metamaterials in radio frequency, microwave, and optical appliances. Meanwhile, the introduction of metamaterials with a negative refractive index was utilised to shield an object from view, termed cloaking [3]. Metamaterials are usually prepared by repeating the unit cell or proposed pattern, taking into consideration the wavelength of the 
desired phenomenon. Moreover, the properties of metamaterials depend on their design, size, forms, or assembly instead of the material ingredients [4]. In short, uncommon precise orientation, shapes, or sizes determine the unique or smart novel properties of metamaterials, particularly EM properties. Material researchers are passionate and interested in this field to harvest the benefits of metamaterials (absorbing, cloaking, blocking, bending or enhancing EM radiation) due to their novel EM properties [5,6].

The extant literature has indicated the uses of metamaterials in many applications. For instance, the L band stretchy metamaterial with an EMR of 4.8 using nickel aluminate substrate was designed for a sensing application [7]. Sekip Dalgac et al. [8] presented an S-shaped metamaterial comprising a rectangular split-ring resonator to forecast moisture in the air and temperature. In 1968, Victor Veselago, a Russian physicist, introduced a theoretical explanation of materials with negative permittivity and negative permeability, called the left-handed (LHM) characteristics [9]. Meanwhile, Pendry et al. revealed an SSR metamaterial based on synthetic magnetic materials with different shapes of SRR (circular, rectangular) on a dielectric substrate [10]. In another study, an S-shaped resonator was bordered by a ground ring [11]. A microstrip line was deployed in this metamaterial for feeding. This sort of metamaterial used an L-band with $1.8 \mathrm{GHz}$ resonance frequency. An amalgamated metamaterial $\left(12 \times 12 \mathrm{~mm}^{2}\right.$ dimension) with an EMR of 7.44 recorded resonances at S, C, and X bands [12]. Meanwhile, a design of a Greek-key pattern operated at a frequency range from 1 to $5 \mathrm{GHz}$ was fabricated on a substrate of Rogers RT5880 $\left(10 \times 10 \mathrm{~mm}^{2}\right.$ dimension). The design measured resonances at $2.4 \mathrm{GHz}, 3.5 \mathrm{GHz}$, and $4 \mathrm{GHz}$ [13]. After three decades, Smith et al. [14] described an experimental demonstration of functioning EM metamaterials using straightly mounding, intermittently, SRR, and thin-wire structures. In 2001, Shelby et al. [15] demonstrated a negative refractive index using a two-dimensional array of repeated unit cells that were also a combination of wire strips and split-ring resonators.

On the other hand, Winston E. Kock developed a material that has analogous features to the metamaterials in 1940 [16]. Flame Retardant-4 (FR-4) material is commonly used to design substrates. Modern technologies demand compounds that are cost-effective, compact, and lightweight, which led to the fabrication of low-cost and easily designed substrates. For example, an ENG metamaterial with an EMR value of 3.5 exhibited EM cloaking operation as it covered the C-band [17]. In another study [18], a dual SRR of hexagonal shape with a gap (GCHSRR) metamaterial $\left(10 \times 10 \mathrm{~mm}^{2}\right.$ dimension) exhibited microwave absorbance uses as it covered the $\mathrm{C}$ - and $\mathrm{X}$-bands. In recent times, metamaterials have been aimed at supporting various frequency bands. Each frequency band has widespread use; the S-band covers a frequency range of $2-4 \mathrm{GHz}$; the $\mathrm{X}$-band covers 8-12 GHz, and the Ku-bands covers 12-18 GHz. The three bands are extensively utilised in satellite communications [19]. Among them, the terrestrial signals can only slightly affect the Ku-band, which operates in a high-frequency range that allows the use of trivialsized dish antennas for VSAT uses. Meanwhile, a metamaterial with a harmonising SRR $\left(5 \times 5 \mathrm{~mm}^{2}\right)$ and EMR of 8 demonstrated a resonance frequency of $7.5 \mathrm{GHz}$ [20].

This study proposed a new and novel metamaterial assembly whose unit cell consists of one SRR with a modified hexagonal-shaped metal stripe. It demonstrated resonance frequencies in the S-, $\mathrm{X}-$, and Ku-bands $(2-4 \mathrm{GHz}, 8-12 \mathrm{GHz}$, and $12-18 \mathrm{GHz})$ in the microwave spectra, apart from indicating negative permittivity and negative refractive index at the same frequencies. Furthermore, the reliability of the performance of the proposed metamaterial was tested using different validation tests. Equivalent circuits were also designed in ADS, HFSS design, $2 \times 1$ and $2 \times 2$ arrays to simulate validation tests. The analyses were performed using different effective parameters like permittivity, permeability and the refractive index, together with transmission and reflection coefficients. The EMR was also used as a comparison of performances in the result section. 


\section{Design of the Unit Cell and Simulation}

A vivid illustration of the projected metamaterial unit cell illustrated in Figure 1a is a combination of a square-shaped single slit resonator (SSR) and a modified hexagonal metal strip. Figure $1 \mathrm{~b}$ demonstrates the simulation setup of the unit cell. A $0.035 \mathrm{~mm}$ thick copper (annealed) was used for SSR and modified hexagonal-shaped strip. Moreover, the dielectric substance FR-4 (lossy) with a thickness of $1.6 \mathrm{~mm}$ was used as a substrate with a dielectric constant of 2.2 and a loss tangent of 0.025 . The dimension of the square shapedsubstrate was $9 \times 9 \times 1.6 \mathrm{~mm}^{3}$. The length and width of the unit cell SSR metal strip were defined as W1 and W2, respectively, while the length and width of the substrate were a and $b$, respectively. The slit width $(\mathrm{g})$ and height were each $0.2 \mathrm{~mm}$, with a $0.5 \mathrm{~mm}$ gap $(\mathrm{G})$ between the two strips of the hexagon. However, the width $(\mathrm{w})$ of all the metal strips in SSR was $0.5 \mathrm{~mm}$, and the width of the hexagonal arm strips (y) was $1 \mathrm{~mm}$. According to the simulation setup of the proposed unit cell (Figure 1b), an EM wave was applied along the z-axis. In addition, a perfect electrical and magnetic boundary were applied consecutively along the $\mathrm{x}$-axis and y-axis. The dimensions of the unit cell, including all parametric values, are listed in Table 1.

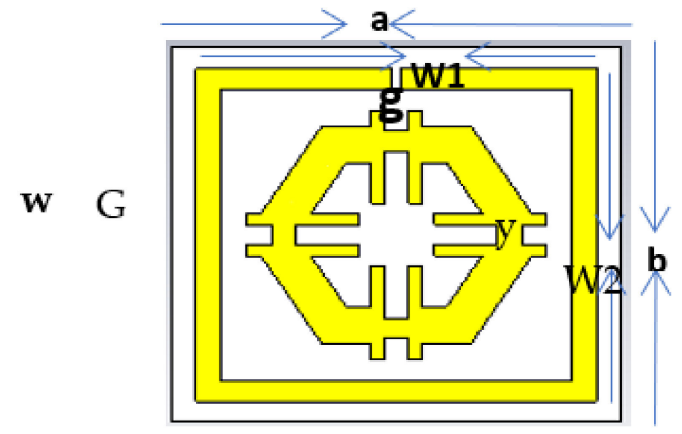

(a)

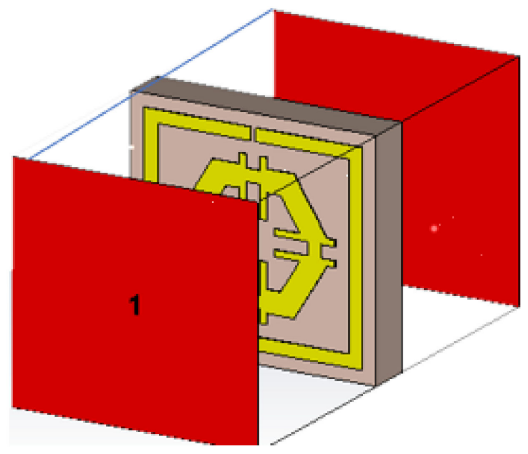

(b)

Figure 1. (a) Unit cell and (b) Simulation arrangement.

Table 1. Unit cell parameters.

\begin{tabular}{ccc}
\hline Parameter & Dimension $(\mathbf{m m})$ & Parameter Dimension $(\mathbf{m m})$ \\
\hline a & 9 & G 0.50 \\
b & 9 & g 0.20 \\
W1 & 8 & W 0.50 \\
W2 & 8 & y 1 \\
\hline
\end{tabular}

\section{Effective Medium Parameters Extraction Method}

The EM simulator CST was applied for the mathematical and geometrical analyses based on a definite integration procedure. This method provided tractability in different composite symmetrical structure modelling and integrated the arbitrary distribution of materials with their properties. Simultaneously, a frequency-domain solver using a tetrahedral mesh in CST was used to simulate the proposed structure. The EM waves were fixed to promulgate to the z-axis. Perfect electric and magnetic fields were applied along the $\mathrm{x}$ and y-axes as a boundary condition to simulate $2.0-18.0 \mathrm{GHz}$ of the resonance frequency. Additionally, transmission coefficient (S21), permittivity $\left(\varepsilon_{\mathrm{r}}\right)$, and refractive coefficient $\left(n_{r}\right)$ were evaluated to determine the EM properties of the proposed structure using the Nicolson-Ross-Weir technique [21].

$$
\text { Permitivity, } \varepsilon_{\mathrm{r}}=\frac{\mathrm{c}}{\mathrm{j} \pi \mathrm{fd}} \times \frac{\{1-(\mathrm{S} 21+\mathrm{S} 11)\}}{\{1+(\mathrm{S} 21+\mathrm{S} 11)\}}
$$




$$
\begin{array}{r}
\text { Permeability, } \mu_{r}=\frac{\mathrm{c}}{\mathrm{j} \pi \mathrm{fd}} \times \frac{\{1-(\mathrm{S} 21-\mathrm{S} 11)\}}{\{1+(\mathrm{S} 21-\mathrm{S} 11)\}} \\
\text { And } n_{r}=\sqrt{\varepsilon_{\mathrm{r}} \mu_{r}} \\
\text { Or, } n_{r}=\frac{\mathrm{c}}{\mathrm{j} \pi \mathrm{fd}} \sqrt{\frac{\{1-(\mathrm{S} 21+\mathrm{S} 11)\}}{\{1+(\mathrm{S} 21+\mathrm{S} 11)\}} \times \frac{\{1-(\mathrm{S} 21-\mathrm{S} 11)\}}{\{1+(\mathrm{S} 21-\mathrm{S} 11)\}}} \\
=\frac{\mathrm{c}}{\mathrm{j} \pi \mathrm{fd}} \sqrt{\frac{(\mathrm{S} 21-1)^{2}-\mathrm{S} 11^{2}}{(\mathrm{~S} 21+1)^{2}-\mathrm{S} 11^{2}}}
\end{array}
$$

where, $c, f$, and $d$ represent the speed of light, frequency, and the thickness of the substrate, respectively. S11 represents the reflection coefficient, and S21 is denoted the transmission coefficient. To obtain the refractive index $\left(n_{r}\right)$, relative permittivity $\left(\varepsilon_{r}\right)$, and permeability $\left(\mu_{\mathrm{r}}\right)$, MATLAB codes were established based on Equations (1)-(3). The results of the parameters extracted through the NRW method was compared with the CST results.

\section{Parametric Study}

\subsection{Design Procedure}

To maximise the benefit from a design, the best design was selected among the available trial designs. An iterative method was performed to assess the response of the unit cell. The length, width, the distance between the SSR, and the size of the slits were changed based on trial-and-error. Figure 2 represents some of the trial designs. Design- 1 of Figure 2 contains a single slit square ring with a uniform width of $0.50 \mathrm{~mm}$. This is an SSR with a dimension of $8 \times 8 \mathrm{~mm}^{2}$ and a thickness of $0.035 \mathrm{~mm}$ with a split gap of $0.40 \mathrm{~mm}$. This SSR demonstrated two major responses at $3 \mathrm{GHz}$ and $10 \mathrm{GHz}$. Design-2 illustrates a hexagonal loop with a width of $1 \mathrm{~mm}$ that was added to Design-1 (Figure 2b). Following the simulation, the resonance frequencies recorded were at $3 \mathrm{GHz}, 10 \mathrm{GHz}$, and $17 \mathrm{GHz}$. Meanwhile, the modification to Design-2 gave rise to Design-3, which had an addition of two metal strips that were $6 \mathrm{~mm}$ long and a split gap of $1 \mathrm{~mm}$. This modified design recorded resonances at $3 \mathrm{GHz}$ and $10 \mathrm{GHz}$. Finally, the placement of two more metal strips with the same split gap in Design-3 in a horizontal orientation on the hexagon arms was represented as the proposed design (Figure $2 \mathrm{~d}$ ). The proposed design measured three major frequencies at $2.89 \mathrm{GHz}, 9.42 \mathrm{GHz}$, and $15.16 \mathrm{GHz}$. Figure 3 indicates the transmission coefficient (S21) for the four different designs.

The proposed design has a substrate with a dimension of $9 \times 9 \times 1.6 \mathrm{~mm}^{3}$; the length and wide of the SSR unit cell metal strips were $W 1=8 \mathrm{~mm}$ and $W 2=8 \mathrm{~mm}$, with a split width (g) of $0.20 \mathrm{~mm}$. Moreover, $\mathrm{G}$, the split gap between the placed metal bar strips of the hexagon was measured at $1 \mathrm{~mm}$ with every metal strip at $0.5 \mathrm{~mm}$ width. The proposed structure demonstrated a maximum number of resonance (frequency bands) with negative permittivity and negative index. The dimensions of the suggested metamaterial unit cell, including all designs tranmission coefficients results values, are listed in Table 2.

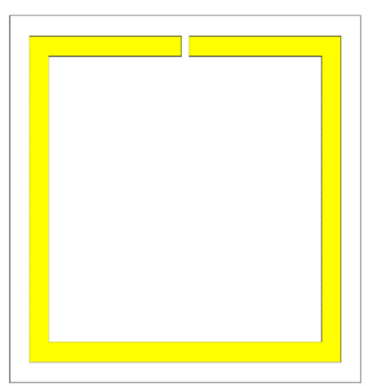

(a)

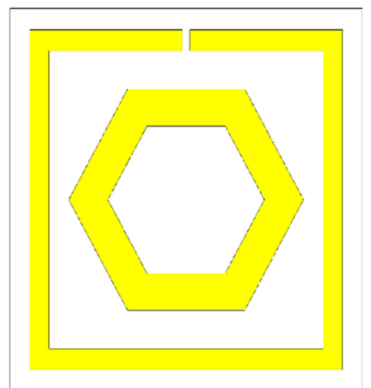

(b)

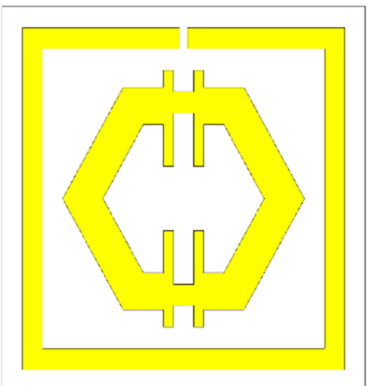

(c)

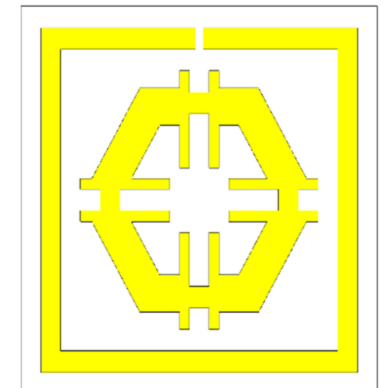

(d)

Figure 2. Trial design: (a) Design-1, (b) Design-2, (c) Design-3, (d) proposed design. 


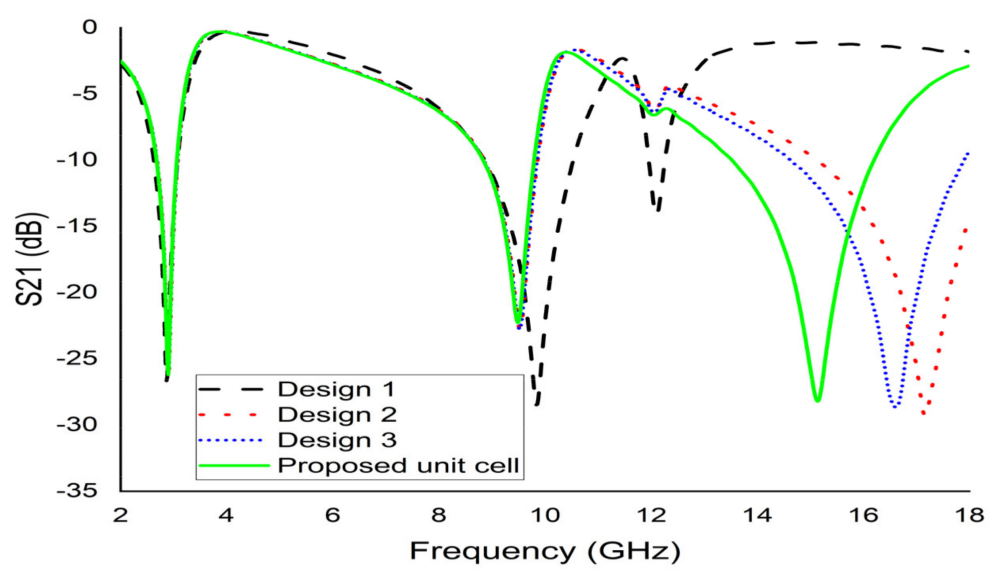

Figure 3. S21 for various designs.

Table 2. S21 for various designs.

\begin{tabular}{ccccc}
\hline Subdesign & $\begin{array}{c}\text { Resonance } \\
\text { Frequency (GHz) }\end{array}$ & Types Structure & Resonance Apex (dB) & Covering Bands \\
\hline Design-1 & $2.9,10$ & SSR & $-27.44,-26.19$ & $\mathrm{~S}, \mathrm{X}$ \\
Design-2 & $3,9.8,17.33$ & SSR+ Hexagon & $-25.76,-20.83,-28.28$ & $\mathrm{~S}, \mathrm{X}, \mathrm{Ku}$ \\
Design-3 & $2.89,10,17.2$ & Modified hexagon & $-27.4,-30,-29$ & $\mathrm{~S}, \mathrm{X}, \mathrm{Ku}$ \\
Proposed design & $2.89,9.42,15.16$ & Formatted hexagon & $-25,-22.24,-28$ & $\mathrm{~S}, \mathrm{X}, \mathrm{Ku}$ \\
\hline
\end{tabular}

\subsection{Effects of Changing of the Unit Cell Size}

To optimise the size of the proposed metamaterial, the unit cell with different substrate sizes were simulated. Based on Figure 4, the substrate of sizes $11 \mathrm{~mm}$ and $13 \mathrm{~mm}$ with a thickness of $1.6 \mathrm{~mm}$ exhibited three resonances with low bandwidth. Contrarily, the

$9 \mathrm{~mm}$ substrate with the same thickness demonstrated three major resonances at $2.89 \mathrm{GHz}$, $9.42 \mathrm{GHz}$, and $15.16 \mathrm{GHz}$. Hence, the $9 \times 9 \times 1.6 \mathrm{~mm}^{3}$ dimension was fixed as the proposed unit cell size.

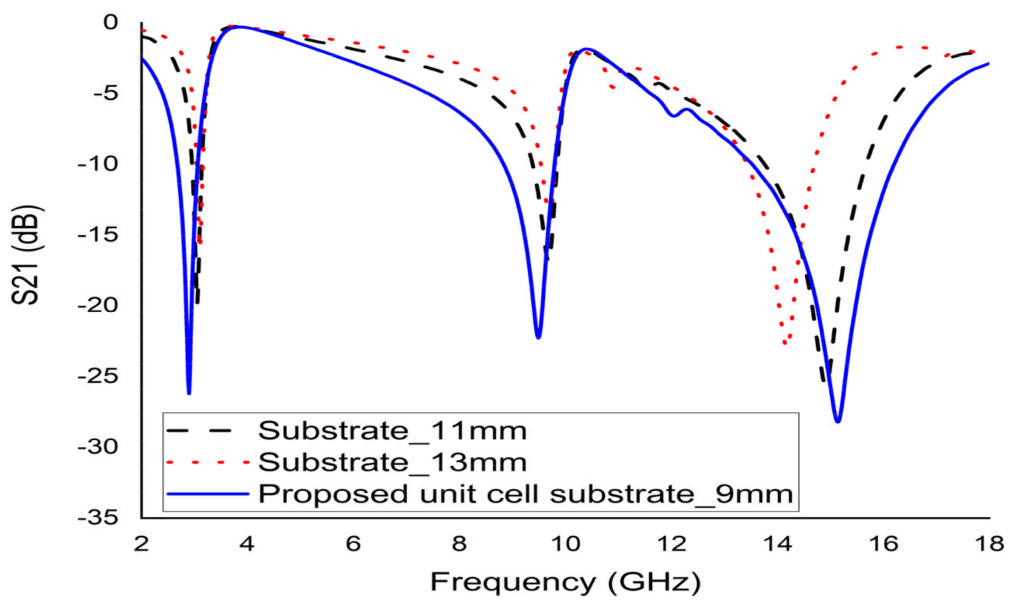

Figure 4. S21 for the different sized unit cell.

\subsection{Effects of Changing Substrate Properties}

According to a study, two types of Rogers (RT 5880 and RT 6002) and an FR-4 (lossy) with the same dimension $\left(9 \times 9 \times 1.6 \mathrm{~mm}^{3}\right)$ were used to observe the properties of different substrates materials. The loss tangent and paramagnetic constant for substrate RT 5880 were 0.0004 and 2.2, as for RT 6002 were 0.0037 and 3.48, respectively. The S21 depicted in Figure 5 indicated three sharp resonances with narrow bandwidths for RT 5880 and RT 6002. Substrate FR-4 (Dk 2.2 and loss tangent 0.025) demonstrated three resonances 
with satisfactory bandwidth covering S-, X-, and Ku-bands. A high EMR of 11.53 was calculated for the first resonance frequency $(2.89 \mathrm{GHz})$. Therefore, FR-4 (lossy) was selected as a substrate material for the fabrication of the proposed unit cell.

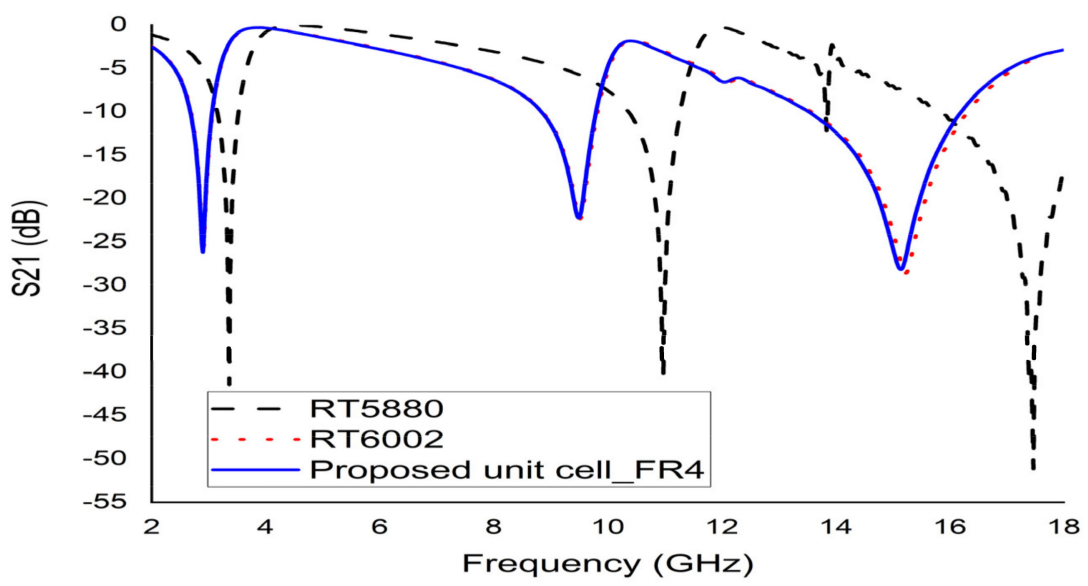

Figure 5. S21 for different substrate materials.

\subsection{Effects of Changing the EM Field Propagation Direction}

The electric field (Ey) was applied towards the y-axis, while the magnetic field (Hx) was applied towards the $x$-axis (Figure $6 \mathrm{a}$ ). The resonances recorded at both axes were $6 \mathrm{GHz}$ and $15 \mathrm{GHz}$, respectively. If the fields are interchanged with each other, an electric field (Ex) was applied in $x$-direction and the magnetic field (Hy) in y-direction (Figure 6b); three major resonances were observed at $2.89 \mathrm{GHz}, 9.42 \mathrm{GHz}$, and $15.16 \mathrm{GHz}$ (Figure 7).

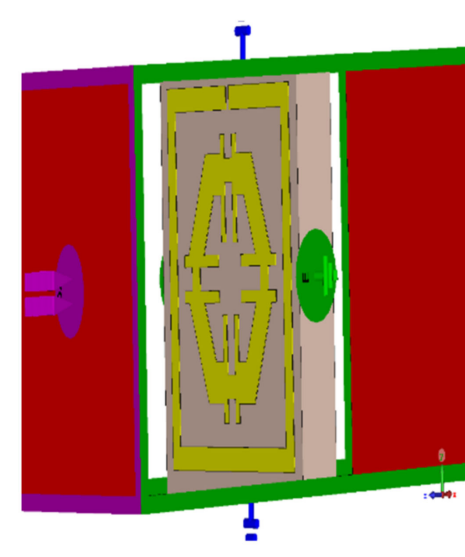

(a)

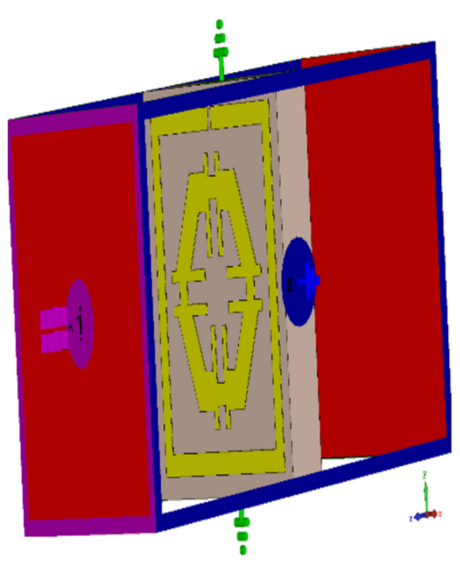

(b)

Figure 6. Simulation setup for changing field propagation, (a) magnetic field applied $x$-axis (b) magnetic field applied $y$-axis. 


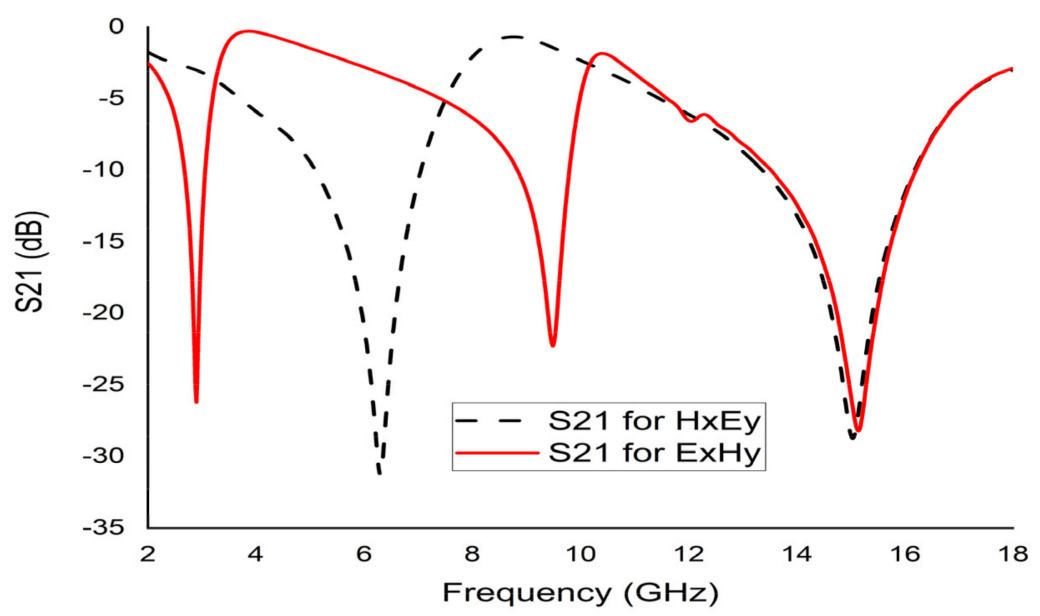

Figure 7. S21 for changing field direction.

\section{Surface Current, Electric Field, and Magnetic Field Analysis}

The EM characteristics of metamaterials rely on different forces and fields, which are depended upon to produce charge. Maxwell's curl equations are the best tools to explain the generated electric and magnetic fields [22].

$$
\begin{gathered}
\nabla \times H=J+\frac{\partial D}{\partial t} \\
\nabla \times E=\frac{\partial H}{\partial t}
\end{gathered}
$$

where vector operator, $\nabla=\left[\frac{\partial x}{\partial t}, \frac{\partial y}{\partial t}, \frac{\partial z}{\partial t}\right]$.

Equations (4) and (5) are not sufficient to describe the relationship between matter, the electric field, and the magnetic field. However, these limitations were solved using the following equations.

$$
\begin{aligned}
& \varepsilon(t)=\frac{D(t)}{E(t)} \\
& \mu(t)=\frac{B(t)}{H(t)}
\end{aligned}
$$

The equations presented above were used to assess the surface current, magnetic, and electric fields functions. The current distribution at three different resonance frequencies was $2.89 \mathrm{GHz}, 9.42 \mathrm{GHz}$, and $15.16 \mathrm{GHz}$ (Figure 8). The current flow differs with the change of frequency. Based on Figure $9 \mathrm{a}-\mathrm{c}$, the outside square ring of the unit cell was determined to have been strongly dominated by the surface current. In other words, it meant that the outer ring belonged to the resonance at $2.89 \mathrm{GHz}$. Moreover, it was notable that the hexagonal ring was also subsidised as a major part of the current. The magnetic field distribution for the proposed unit cell at various resonance frequencies $(2.89 \mathrm{GHz}$, 9.42 GHz, and $15.16 \mathrm{GHz}$ ) is depicted in Figure 10a-c. 


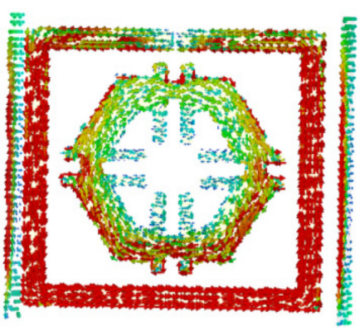

(a)

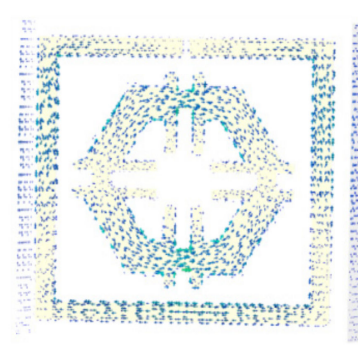

(b)

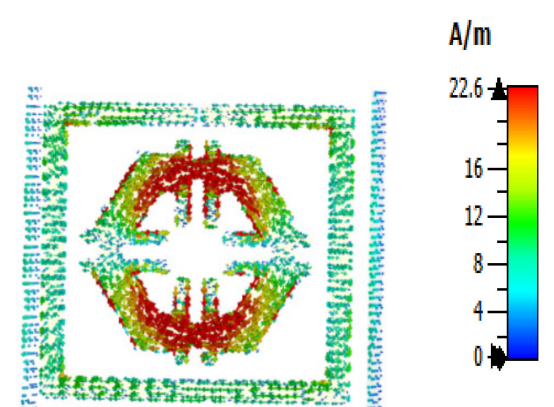

(c)

Figure 8. Surface current: (a) $2.89 \mathrm{GHz}$, (b) $9.42 \mathrm{GHz}$, and (c) $15.16 \mathrm{GHz}$.

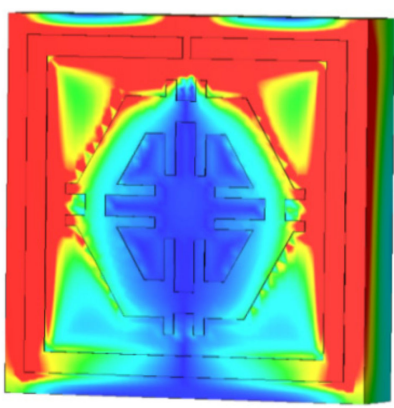

(a)

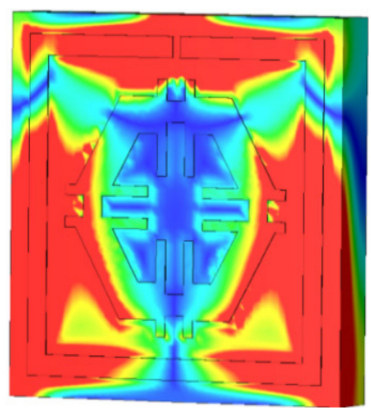

(b)

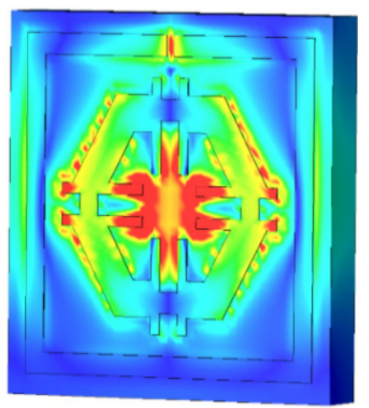

(c)

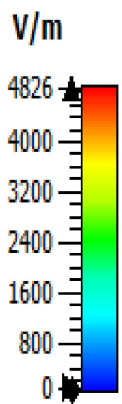

Figure 9. Electric field pattern: (a) $2.89 \mathrm{GHz}$, (b) $9.42 \mathrm{GHz}$, and (c) $15.16 \mathrm{GHz}$.

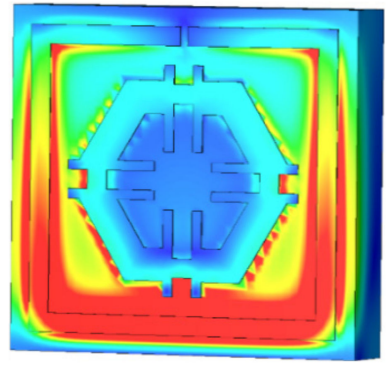

(a)

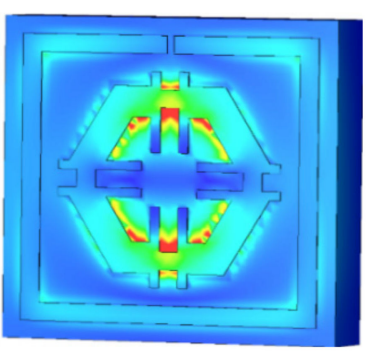

(b)
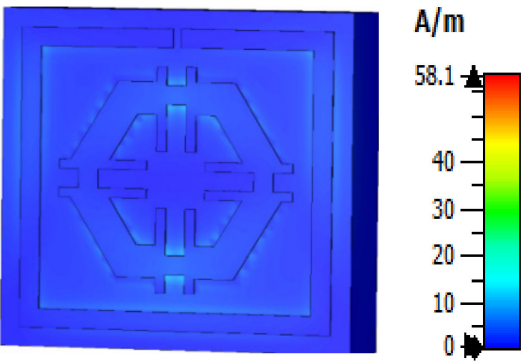

(c)

Figure 10. Magnetic field distribution (a) $2.89 \mathrm{GHz}$, (b) $9.42 \mathrm{GHz}$, and (c) $15.16 \mathrm{GHz}$.

According to the Biot-Savart and Ampere's law, a magnetic field is produced due to the motion of charged particles or electrical charges [23]. The flow of higher electrical charges increased the strength of the magnetic field that was observable from the $\mathrm{H}$ field (Figure 10). The magnetic field centered in a wire at a distance $(r)$ follows the equation (using the Biot-Savart law), $B=\frac{\mu_{0} I}{2 \pi r}$, where $\mu_{0}$ is the permeability of free space. A similar outcome was also yielded in the E field (Figure 9). Compared to the electric field pattern presented in Figure 5 with the $\mathrm{H}$ field presented in Figure 6, it is evident that fewer changes in the $\mathrm{H}$ field at a particular point also measures low electric field intensity. Furthermore, the electric field intensity at the point of splits was higher since the split in the resonator ring gap formed a capacitor. 


\section{Circuit Model of the Projected Metamaterial Unit Cell}

The proposed metamaterial involved both inductive and capacitive components. All the metal bars and the metal strips of the rings (both SRR and hexagonal) acted as inductors, while the gaps within the metal bar or rings formed capacitors. Therefore, an LC resonance circuit was formed in this metamaterial unit cell. As such, the resonance frequency (f) can be derived using Equation (8) [17].

$$
f=\frac{1}{2 \pi(\mathrm{LC})^{\frac{1}{2}}}
$$

where $\mathrm{L}$ is inductance, and $\mathrm{C}$ is capacitance. The capacitance of the capacitor formed by the slits can be calculated using Equation (9).

$$
C=\epsilon_{0} \in_{r} \frac{\mathrm{A}}{\mathrm{d}}(\mathrm{F})
$$

where, $\epsilon_{0}$ and $\epsilon_{r}$ represent the permittivity in free space and the relative permittivity, respectively, and A is the cross-sectional area of the conducting strip, while $\mathrm{d}$ is the split gap.

$$
L(n H)=2 \times 10^{-4} \mathrm{l}\left[\ln \left(\frac{\mathrm{l}}{\mathrm{w}+\mathrm{t}}\right)+1.193+0.02235\left(\frac{\mathrm{w}+\mathrm{t}}{\mathrm{l}}\right)\right] \mathrm{K}_{\mathrm{g}}
$$

Here, $\mathrm{K}_{\mathrm{g}}=$ Correction factor, $\mathrm{w}=$ width, $\mathrm{l}=$ length, and $\mathrm{t}=$ thickness of the strip

Figure 11 represents an estimated equivalent circuit for the designed metamaterial unit cell. At the equivalent circuit, L1, L2, L3, L4, L5, and L6 refer to the inductors, while $\mathrm{C} 1, \mathrm{C} 2, \mathrm{C} 3, \mathrm{C} 4$, and $\mathrm{C} 5$ are capacitors. The circuit was optimised and simulated using the advanced design system (ADS). As such, inductor L1 and capacitor C1 were responsible for the first resonance $(2.89 \mathrm{GHz})$, where L1 regulated the resonance frequency of S21, with $\mathrm{C} 1$ as the biasing factor that modifies the magnitude. Whereas $\mathrm{C} 3$ is the coupling capacitor, L3 and L4 refer to two series inductors, while L5 and L6 refer to two parallel inductors that contribute to the other two resonances. Figure 12 illustrates a comparative view of the simulated S21 derived from the CST and ADS describing the closest similarities between these two S21 values. However, the impedance was derived for equivalent circuits based on the Thevenin theorem.

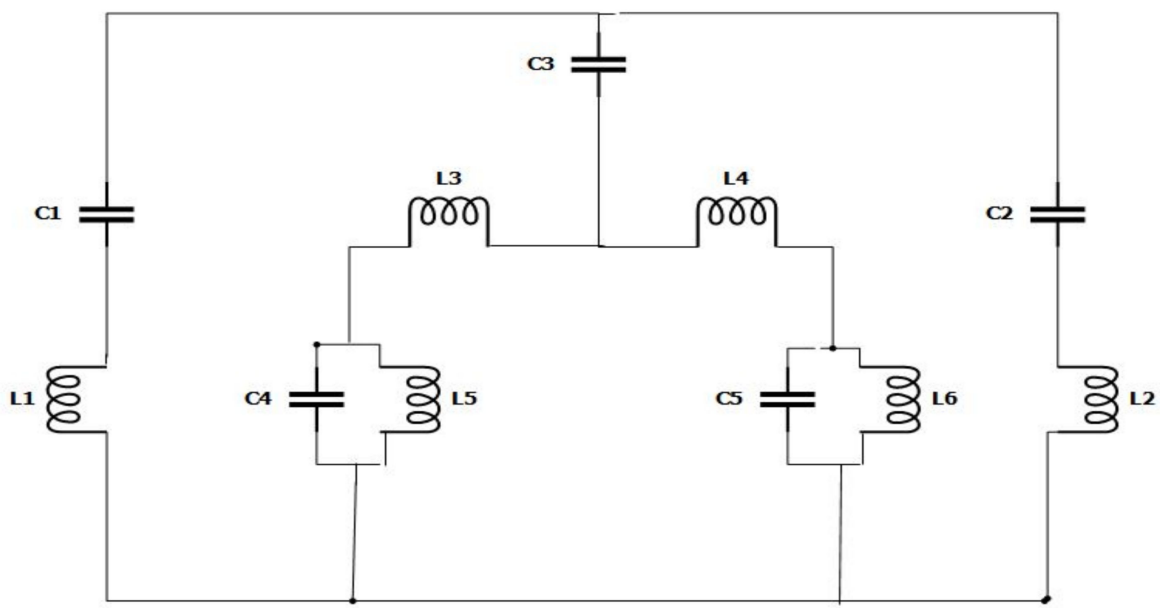

Figure 11. Equivalent circuit model of a unit cell. 


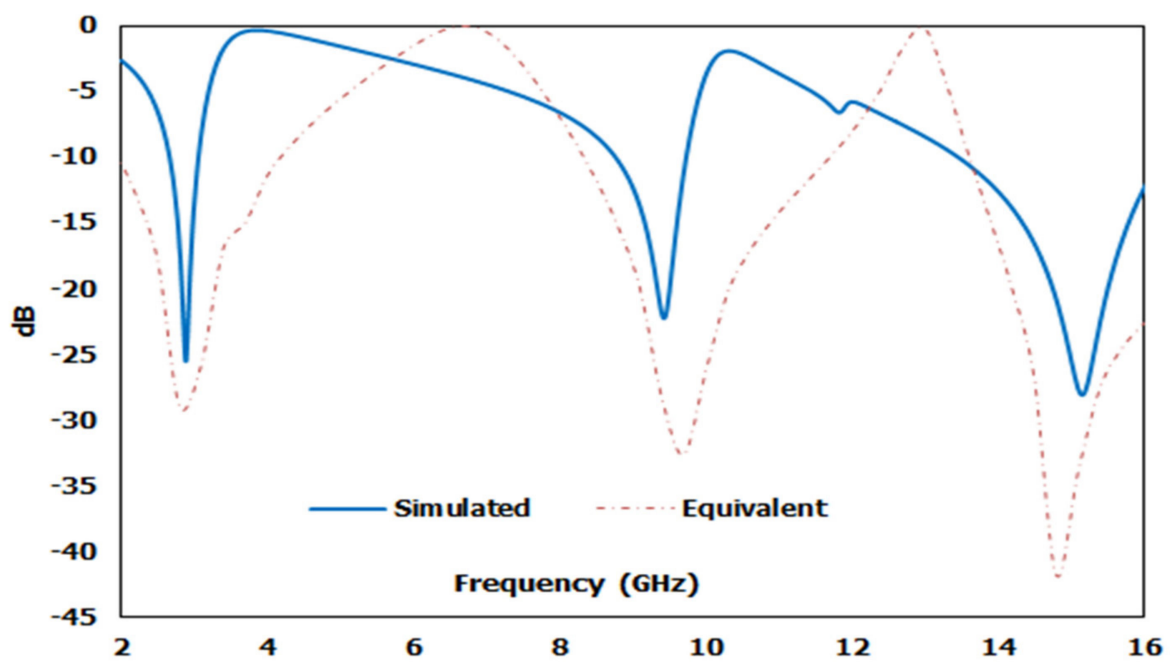

Figure 12. Comparison of CST and ADS transmission coefficient S21 results.

\section{Results and Discussion}

The mathematical analyser CST was employed in this study to determine the Sparameters and different coefficients of the unit cell. Figure 13 represent the reflection coefficient (S11) and S21. The unit cell recorded resonance frequencies at $2.89 \mathrm{GHz}, 9.42 \mathrm{GHz}$, and $15.16 \mathrm{GHz}$ with $-25 \mathrm{~dB},-22.24 \mathrm{~dB}$, and $-28 \mathrm{~dB}$ amplitude, respectively. As for S11, negative peaks were observed at $3.78 \mathrm{GHz}$ and $10.20 \mathrm{GHz}$ with $-23.72 \mathrm{~dB}$ and -8.98 $\mathrm{dB}$ amplitude, respectively. Bandwidths of $0.39 \mathrm{GHz}$ at S-band, $0.94 \mathrm{GHz}$ at X-band, and $2.64 \mathrm{GHz}$ at $\mathrm{Ku}$-band are also depicted in Figure 13. Moreover, the numerical data were extracted for permittivity, permeability, and refractive index using MATLAB code (Figures 14-16). According to Figure 13, it is found that every resonance of S21 was tracked by an S11 minimum. Since every minimum frequency of S21 was lower than that of the corresponding S11 minimum frequency, every resonance was treated as an electrical resonance in the unit cell. Meanwhile, Figure 14; Figure 15 represent the results of permittivity and permeability. It is observed that the value permittivity goes through from maximum to minimum while resonance takes place in S21. The figures also denoted that minimum values of $\mu$ were derived from minimum S11 points. The values of permittivity changed from positive to negative when $\mu$ positively changed the quantity. Since the refractive index was related to the frequency, the near-null property at the negative permittivity region is depicted in Figure 16. Due to the negative permittivity of the projected unit cell in a certain frequency region, the proposed design was termed a negative-permittivity (ENG) metamaterial. Applying the Drude function [24].

$$
\varepsilon(\omega)=1-\frac{\omega_{p}^{2}}{\omega(\omega+i \Gamma)}
$$

where $\Gamma$ is the attenuation function due to energy disintegration in the plasmons, and $\omega_{p}$ is the plasmon frequency which is determined by $\omega_{p}=\frac{d q^{2}}{\epsilon_{0} m}$. Also, $\mathrm{d}$ represents effective density, $q$ for electron charge, $\epsilon_{0}$ for permittivity of free space, and $m$ for the mass of the electron. If $\Gamma \approx 0$ then $\omega<\omega_{\mathrm{p}}$ and then permittivity $(\varepsilon)$ will be negative. Thus, the EM wave will not propagate. This unique property (negative permittivity) of the metamaterial can widely be used in various types of communication systems, for instance, bandwidth improvement of the antenna [25] and microwave filter. Meanwhile, the negative refractive index property can be utilised for cloaking, sensing, and enhancing antennas. To validate the authentication of the result, the unit cell was simulated by CST and HFSS (S11 and S21) are illustrated in Figure 17. The extracted parameters and their respective frequencies values are listed in Table 3 and comparison of resonance frequencies between the unit cell and arrays are listed in Table 4. 


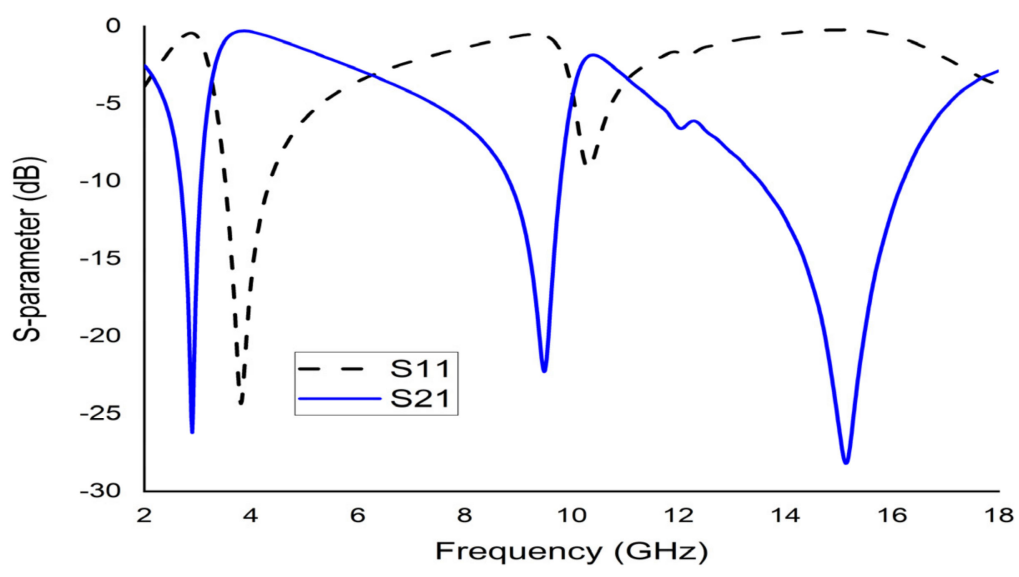

Figure 13. CST results of S11 and S21 of the unit cell.

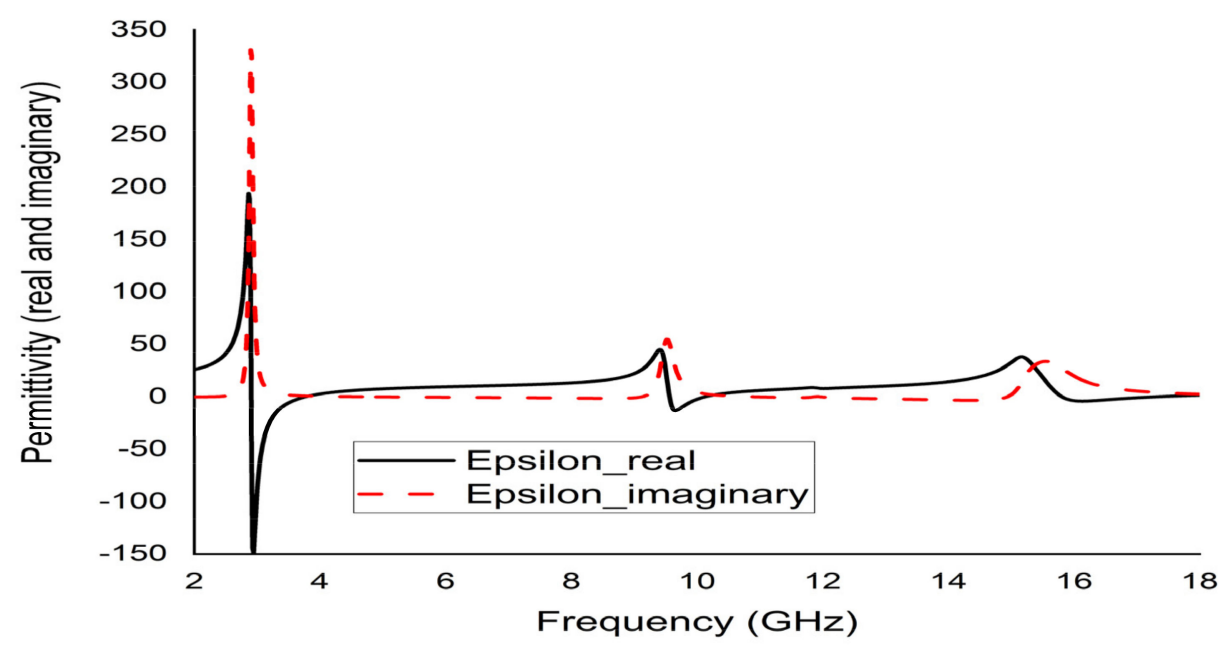

Figure 14. Real and imaginary permittivity $(\varepsilon)$ of the unit cell.

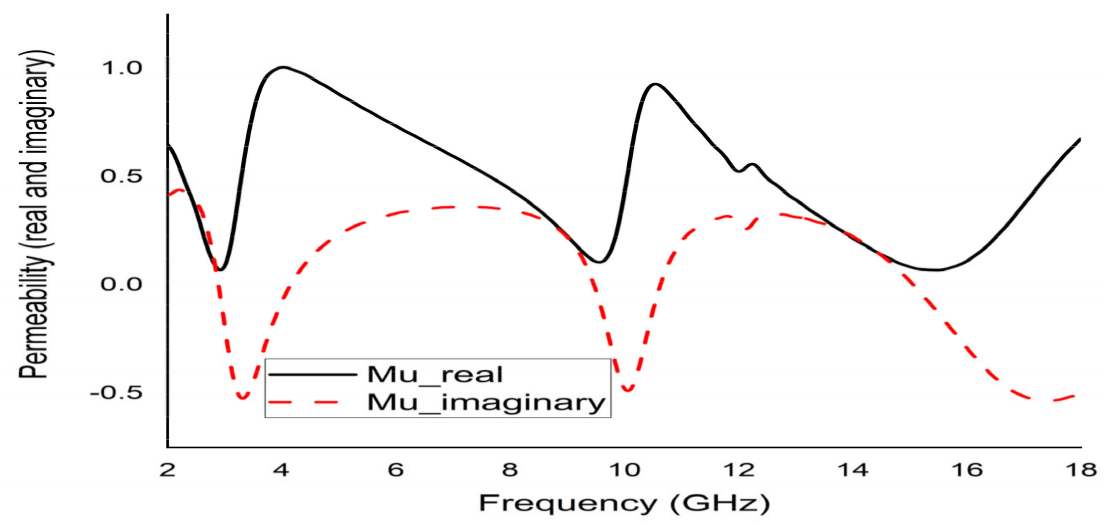

Figure 15. Real and imaginary permeability $(\mu)$ of the unit cell. 


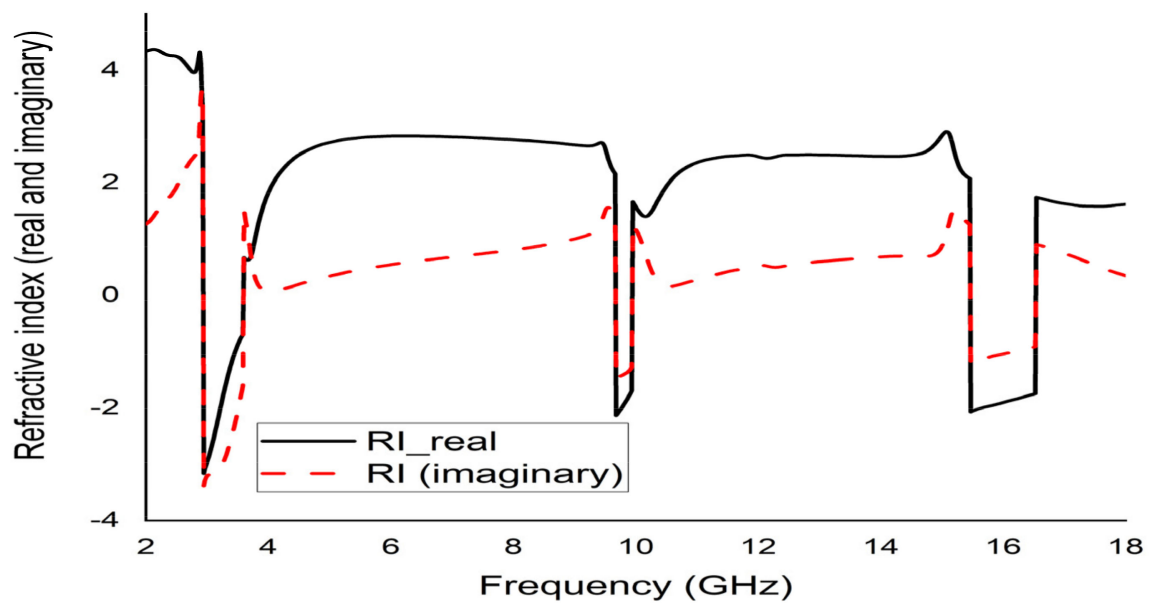

Figure 16. Real and imaginary refractive index (n) of the unit cell.

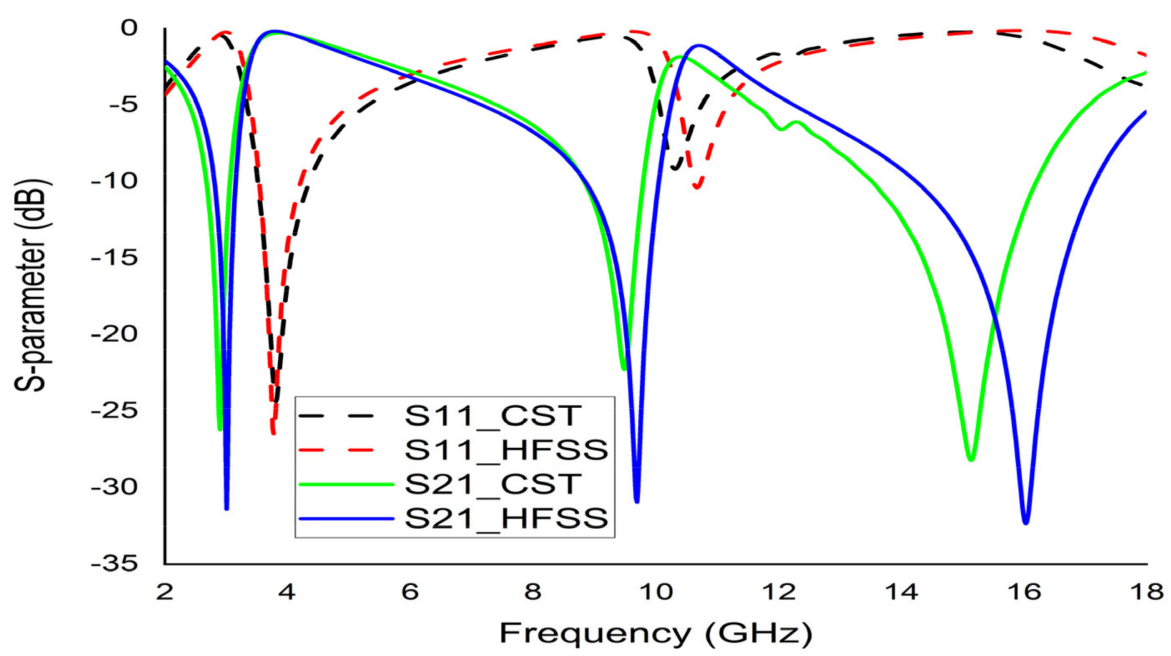

Figure 17. Validation of S11 and S21 of the unit cell based on CST and HFSS.

Table 3. Extracted properties of the unit cell.

\begin{tabular}{ccc}
\hline Parameter & Frequency $(\mathrm{GHz})$ & Extracted Property \\
\hline Transmission coefficient, S21 & $2.89,9.42,15.16$ & $\mathrm{~S} 21<-20 \mathrm{~dB}$ \\
Permittivity, $\varepsilon_{\mathrm{r}}$ & $2.9,9.54,15.36$ & $\varepsilon_{\mathrm{r}}<0$ \\
Permeability, $\mu_{\mathrm{r}}$ & $2.86,9.47,15.60$ & $\mu_{\mathrm{r}} \approx 0$ \\
Refractive index, $\mathrm{n}$ & $2.90,9.60,15.47$ & $\mathrm{n}<0$ \\
\hline
\end{tabular}

Table 4. Comparison of resonance frequencies among the unit cell and arrays.

\begin{tabular}{ccccc}
\hline $\begin{array}{c}\text { Types of } \\
\text { Simulation }\end{array}$ & Unit Cell & $\mathbf{2} \times \mathbf{1}$ Array & $\mathbf{2} \times \mathbf{2}$ Array & $\begin{array}{c}\text { Max. Shift of } \\
\text { Frequency (\%) }\end{array}$ \\
\hline $\begin{array}{c}\text { 1st resonance } \\
(\mathrm{GHz})\end{array}$ & 2.89 & 2.87 & 2.87 & 0.69 \\
$\begin{array}{c}\text { 2nd resonance } \\
(\mathrm{GHz})\end{array}$ & 9.42 & 9.32 & 9.29 & 1.3 \\
$\begin{array}{c}\text { 3rd resonance } \\
(\mathrm{GHz})\end{array}$ & 15.16 & 15.12 & 15.14 & 0.26 \\
\hline
\end{tabular}




\section{Array Structure}

The unit cell does not function satisfactorily as an independent unit. Hence, an array of unit cells is the best technique to obtain the expected EM properties from a metamaterial. The $2 \times 1$ and $2 \times 2$ arrays of the proposed unit cell with the same substrate material were simulated by CST (Figure 18a,b). A parametric study was performed using $2 \times 1$ and $2 \times 2$ arrays to investigate the coupling effect between the designed unit cells for different combinations of the array recorded nearly identical S21 responses to the unit cell. Therefore, the efficiency of the arrays was manifested. Figure 19 demonstrates the graphical presentation of S11 and S22 comparison by CST for array combination and the proposed unit cell. Although the resonance frequencies were a little distorted in the new array metamaterial, the triple band resonance properties were still functioning based on the simulated results of the array presented in Figure 19. The authentication between the previous configurations and proposed configuration values are listed in Table 5.

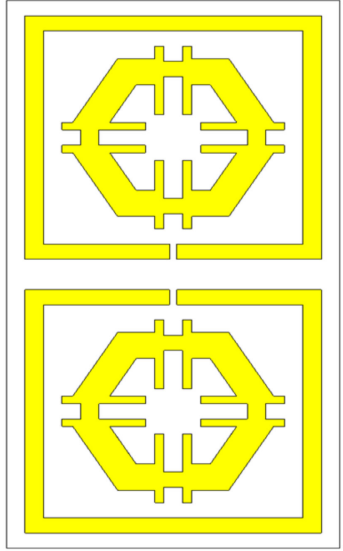

(a)

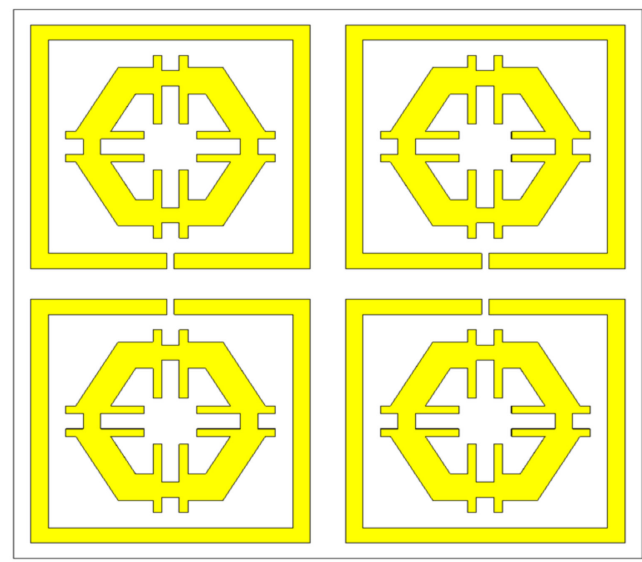

(b)

Figure 18. (a) $2 \times 1$ array, and (b) $2 \times 2$ array.

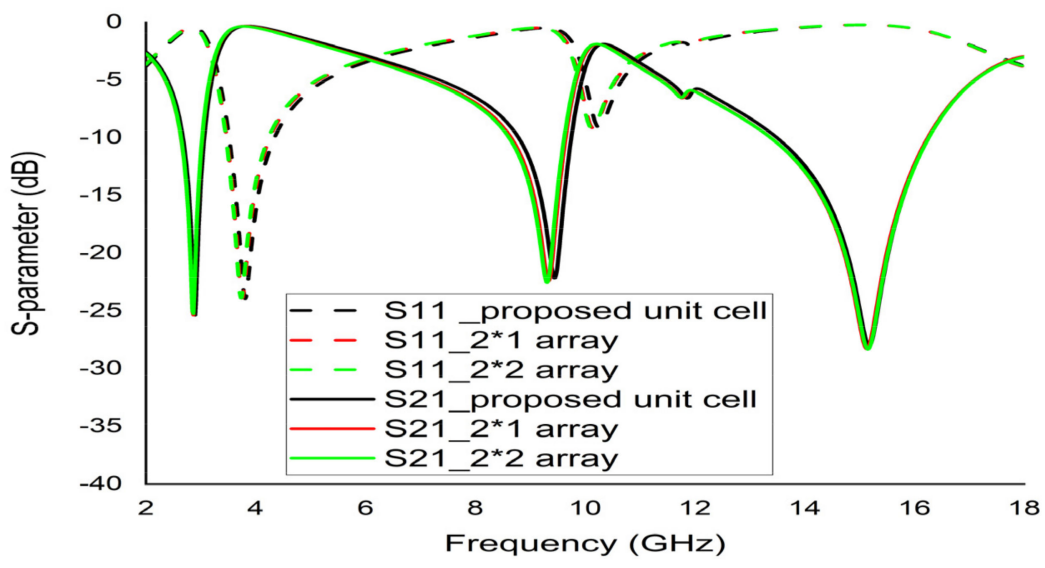

Figure 19. Comparison of S11 and S21 between the unit cell and array combinations. 
Table 5. Authentication between the previous configurations and proposed configuration.

\begin{tabular}{ccccc}
\hline Author Name & Design Shape & Dimension $\left.\mathbf{( m m}^{\mathbf{3}}\right)$ & $\begin{array}{c}\text { Metamaterial } \\
\text { Type }\end{array}$ & EMR $(\boldsymbol{\lambda} / \mathbf{L})$ \\
\hline Mallik et.al. & U & $25 \times 25 \times 1$ & LHM & 1.99 \\
Zhou Z et.al. & Modified H & $9 \times 9 \times 1$ & Chiral & 3.50 \\
Islam et.al & $\mathrm{H}$ & $30 \times 30 \times 1.6$ & LHM & 3.65 \\
Hossain et.al. & $\mathrm{G}$ & $12 \times 12 \times 1.6$ & $\mathrm{NIM}$ & 11.90 \\
Faruque et.al. & $\mathrm{SSR}$ & $10 \times 10 \times 1.6$ & LHM & 9.10 \\
Hossain et.al. & $\mathrm{C}$ & $12 \times 12 \times 1.6$ & $\mathrm{NM}$ & 7.44 \\
Hasan et.al. & Modified G & $10 \times 10 \times 1.6$ & SNM & 3.98 \\
Proposed metamaterial & Formatted hexagon & $9 \times 9 \times 1.6$ & ENG & 11.53 \\
\hline
\end{tabular}

On the other hand, the symmetric pattern of the used SSR and hexagonal metal strip were important in achieving the abovementioned performance. This symmetric pattern of the unit cell helped to decrease the induction effects of the magnetic field. For this reason, the transmission coefficient (S21) is not affected by the harmonic and shows almost the same scattering behaviour and EM properties in the full frequency spectrum.

\section{Conclusions}

This study discussed a metamaterial with negative permittivity designed on an FR4 substrate with resonance frequencies at $2.89 \mathrm{GHz}$ (S-band), $9.42 \mathrm{GHz}$ (X-band), and $15.16 \mathrm{GHz}$ (Ku-band). Such metamaterials are nowadays designed and fabricated to influence EM radiation using new techniques. Many vital properties (optical and EM properties) of various natural materials have been converting through this chemistry. To investigate the performance of the proposed design, the dependency on the dielectric constant and an array or combination of the metamaterial characteristics (here three validations for a single unit cell and array) were incorporated to produce a comparative analysis. An extensive investigation was performed to analyse the surface current, electric field, and magnetic field distribution. The DPS-ENG media properties were also assessed using an EM wave interaction. The vital parameters like permittivity, permeability, and refractive index were determined using MATLAB coding, whereby the results exhibited negative permittivity with a negative refractive index. Whereas, $2 \times 1$ and $2 \times 2$ array metamaterials that were simulated using the same substrate material demonstrated minimal changes in resonance frequencies. On the other hand, the efficiencies of an equivalent circuit that was designed for the desired unit cell were tested via ADS. This result indicated S21 to be very close to the CST results. The proposed unit cell also yielded a resonance frequency of $2.89 \mathrm{GHz}$ with an EMR of 11.53. Since S-, X-, and Ku-bands are widely utilised in satellite and RADAR communications, these tri-band spectra were utilised for microwave communication, long-distance radio communication, and satellite communication. Although this study utilised a simple and compact metamaterial structure, the proposed design manifested triple-band resonance frequencies with excellent EMR value (11.53). In conclusion, this unique metamaterial structure adapted several validation processes that led to its novelty.

Author Contributions: Conceptualization, S.U.A. and M.R.I.F.; methodology, S.U.A., M.J.H. and M.R.I.F.; software, S.U.A. and M.J.H.; validation, S.U.A., M.R.I.F. and M.U.K.; formal analysis, S.U.A., M.J.H. and M.R.I.F.; investigation, S.U.A. and M.R.I.F.; data curation, S.U.A. and M.J.H.; writing—original draft preparation, S.U.A. and M.R.I.F.; writing—review and editing, S.U.A., M.R.I.F., M.J.H., M.U.K., H.O. and S.A.; visualization, S.U.A., M.R.I.F., M.J.H., M.U.K., H.O. and S.A.; supervision, M.R.I.F.; project administration, M.R.I.F.; funding acquisition, H.O. and S.A. All authors have read and agreed to the published version of the manuscript.

Funding: The APC was funded by the Taif University researchers supporting project number (TURSP-2020/287), Taif, Saudi Arabia.

Institutional Review Board Statement: Not Applicable.

Informed Consent Statement: Not applicable.

Data Availability Statement: All the data is available within the manuscript. 
Acknowledgments: We deeply acknowledge Taif University for supporting this research through Taif University Researchers Supporting project number (TURSP-2020/287), Taif University, Taif, Saudi Arabia.

Conflicts of Interest: The authors declare no conflict of interest.

\section{References}

1. Sikder, S.I.; Faruque, M.R.I.; Islam, M.T. A New Double Negative Metamaterial for C-Band Microwave Applications. Adv. Mater. Res. 2014, 974, 33-37. [CrossRef]

2. Suzuki, T.; Harumi, A. Reflectionless zero refractive index metasurface in the terahertz waveband. Opt. Express 2020, 28, 21509-21521. [CrossRef] [PubMed]

3. Islam, S.S.; Faruque, M.R.I.; Islam, M.T. An object-independent ENZ metamaterial-based wideband electromagnetic cloak. Sci. Rep. 2016, 6, 33624. [CrossRef]

4. Hossain, M.J.; Faruque, M.R.I.; Islam, M.T. Effective medium ratio obeying wideband left-handed miniaturized meta-atoms for multi-band applications. J. Electron. Mater. 2018, 47, 1859-1870. [CrossRef]

5. Hossain, M.J.; Faruque, M.R.I.; Islam, M.T. Correction: Perfect metamaterial absorber with high fractional bandwidth for solar energy harvesting. PLoS ONE 2019, 14, e0211751. [CrossRef] [PubMed]

6. Emadi, R.; Reza, S.A.; Zeidaabadi, N. Plasmonic cloaking for irregular inclusions using an epsilon-near-zero region composed of a graphene-silica stack. JOSA B 2018, 35, 643-651. [CrossRef]

7. Sabah, C.; Nesimoglu, T. Design and characterization of a resonator-based metamaterial and its sensor application using microstrip technology. Opt. Eng. 2016, 55, 027107. [CrossRef]

8. Dalgac, S.; Karadağ, F.; Ünal, E.; Özkaner, V.; Bakır, M.; Akgöl, O.; Sevim, U.K.; Delihacıŏlu, K.; Öztürk, M.; Karaaslan, M.; et al. Metamaterial sensor application concrete material reinforced with carbon steel fiber. Mod. Phys. Lett. B 2020, $34,2050097$. [CrossRef]

9. Veselago, V.G. The Electrodynamics of Substances with Simultaneously Negative Values of $\varepsilon$ and $\mu$. Phys. Uspekhi 1968, 10, 509-514. [CrossRef]

10. Pendry, J.B.; Holden, A.; Stewart, W.; Youngs, I. Extremely low frequency plasmons in metallic mesostructures. Phys. Rev. Lett. 1996, 76, 4773. [CrossRef]

11. Enoch, S.G.; Tayeb, G.; Pierre, S.N.; Guérin, P.V. A metamaterial for directive emission. Phys. Rev. Lett. 2002, 89, 213902. [CrossRef] [PubMed]

12. Hossain, M.J.; Faruque, M.R.I.; Islam, M.T. Design and analysis of a new composite double negative metamaterial for multi-band communication. Curr. Appl. Phys. 2017, 17, 931-939. [CrossRef]

13. Zarghooni, B.; Abdolmehdi, D.; Tayeb, A.D. Greek-key pattern as a miniaturized multiband metamaterial unit-cell. IEEE Antennas Wirel. Propag. Lett. 2015, 14, 1254-1257. [CrossRef]

14. Smith, K.L.; Adams, R.S. Spherical spiral metamaterial unit cell for negative permeability and negative permittivity. IEEE Trans. Antennas Propag. 2018, 66, 6425-6428. [CrossRef]

15. Shelby, R.A.; Smith, D.R.; Seldon, S. Experimental verification of a negative index of refraction. Science 2001, 292, 77-79. [CrossRef]

16. Priyanka, A. A Review paper on metamaterial. Int. J. Eng. Sci. Res. Technol. 2014, 3, 612-618.

17. Islam, S.S.; Faruque, M.R.I.; Islam, M.T. An ENG metamaterial based wideband electromagnetic cloak. Microw. Opt. Technol. Lett. 2016, 58, 2522-2525. [CrossRef]

18. Islam, M.S.; Samsuzzaman, M.; Beng, G.K.; Misran, N.; Amin, N.; Islam, M.T. A Gap Coupled Hexagonal Split Ring Resonator Based Metamaterial for S-Band and X-Band Microwave Applications. IEEE Access 2020, 8, 68239-68253. [CrossRef]

19. Moniruzzaman, M.; Islam, M.T.; Islam, M.R.; Misran, N.; Samsuzzaman, M. Coupled ring split ring resonator (CR-SRR) based epsilon negative metamaterial for multiband wireless communications with high effective medium ratio. Results Phys. 2020, 18, 103248. [CrossRef]

20. Almutairi, A.F.; Islam, M.S.; Samsuzzaman, M.; Islam, M.T.; Misran, N.; Islam, M.T. A complementary split ring resonator based metamaterial with effective medium ratio for C-band microwave applications. Results Phys. 2019, 15, 102675. [CrossRef]

21. Hasan, M.M.; Faruque, M.R.I. Left-handed metamaterial using Z-shaped SRR for multiband application by azimuthal angular rotations. Mater. Res. Express 2017, 4, 045801. [CrossRef]

22. Wartak, M.S.; Tsakmakidis, K.L.; Hess, O. Introduction to metamaterials. Phys. Can. 2011, 67, 30-34.

23. Ahamed, E.; Faruque, M.R.I.; Mansor, M.F.B.; Islam, M.T. Polarization-dependent tunneled metamaterial structure with enhanced fields properties for X-band application. Results Phys. 2019, 15, 102530. [CrossRef]

24. Pendry, J.B.; Holden, A.J.; Robbins, D.J.; Stewart, W. Magnetism from conductors and enhanced nonlinear phenomena. IEEE Trans. Microw. Theory Tech. 1999, 47, 2075-2084. [CrossRef]

25. Dawar, P.; De, A. Bandwidth enhancement of RMPA using ENG metamaterials at THz. In Proceedings of the 4th International Conference on Computer and Communication Technology (ICCCT), Allahabad, India, 20-22 September 2013. 